\title{
Nanostructures with Group IV Nanocrystals Obtained by LPCVD and Thermal Annealing of SiGeO Layers
}

Bruno Morana ${ }^{1}$, Andrés Rodríguez ${ }^{1}$, Jesús Sangrador ${ }^{1}$, Tomás Rodríguez ${ }^{1}$, Óscar Martínez ${ }^{2}$, Juan Jiménez ${ }^{2}$, and Andreas Kling ${ }^{3,4}$

${ }^{1}$ Tecnología Electrónica, Universidad Politécnica de Madrid, E.T.S.I.T., Madrid, 28040, Spain

${ }^{2}$ Física de la Materia Condensada, U. de Valladolid, E.T.S.I.I., Valladolid, 47011, Spain

${ }^{3}$ Centro de Física Nuclear, Universidade de Lisboa, Lisbon, 1649-003, Portugal

${ }^{4}$ Instituto Tecnológico e Nuclear, Sacavém, 2686-953, Portugal

\section{ABSTRACT}

Nanocrystals embedded in an oxide matrix have been fabricated by annealing $\mathrm{SiGeO}$ films deposited by LPCVD. The composition of the oxide layers and its evolution after annealing as well as the presence and nature of nanocrystals in the films have been studied by several experimental techniques. The results are analyzed and discussed in terms of the main deposition parameters and the annealing temperature.

\section{INTRODUCTION}

Group IV semiconductor nanocrystals embedded in a dielectric matrix are of interest due to their potential application in Si based optoelectronics and non-volatile memories [1,2]. The fabrication of these nanostructures has been undertaken, among other methods, by oxidation of polycrystalline SiGe layers [3] and crystallization of amorphous SiGe nanoparticles embedded in $\mathrm{SiO}_{2}$ deposited by Low Pressure Chemical Vapour Deposition (LPCVD) [4]. In this work, the possibility of fabricating structures of this kind by LPCVD of SiGeO films and subsequent annealing to segregate the possible excess of $\mathrm{Si}$ and/or Ge in excess in the form of nanocrystals embedded in an oxide matrix has been studied. The nature and evolution of the oxide matrix and the presence of nanocrystals have been analyzed by several experimental techniques as a function of the deposition and annealing conditions.

\section{EXPERIMENTAL}

The deposition of the $\mathrm{SiGeO}$ films was carried out on $\mathrm{Si}$ wafers using $\mathrm{Si}_{2} \mathrm{H}_{6}, \mathrm{GeH}_{4}$ and $\mathrm{O}_{2}$ as reactant gases. The pressure was set at $240 \mathrm{mTorr}$, the deposition temperature was $450{ }^{\circ} \mathrm{C}$ and several $\mathrm{GeH}_{4}: \mathrm{Si}_{2} \mathrm{H}_{6}: \mathrm{O}_{2}$ gas flow ratios were selected in the 0:10:2 to $20: 10: 2$, which correspond to $\mathrm{GeH}_{4} / \mathrm{Si}_{2} \mathrm{H}_{6}$ flow ratios $(\mathrm{F})$ ranging from $\mathrm{F}=0$ to $\mathrm{F}=2$. The as-deposited samples were annealed at temperatures from 600 to $1000{ }^{\circ} \mathrm{C}$ for 1 hour in a $\mathrm{N}_{2}$ atmosphere. Special care has been taken to avoid any oxidation of the films during these processes by using a high flow $(12 \mathrm{l} / \mathrm{min})$ of high purity $\mathrm{N}_{2}$ (N55) and introducing and extracting the gas from the furnace through small diameter tubes. 
The overall structure and composition of the films was studied by Rutherford backscattering spectrometry (RBS). The RBS spectra were taken in Cornell geometry at an incidence angle of $78^{\circ}$ using a $2 \mathrm{MeV} \mathrm{He}^{+}$beam and interpreted by means of the RUMP code [5]. The number of atoms of $\mathrm{Si}, \mathrm{Ge}$ and $\mathrm{O}$ per unit area present in the different films, labelled [Si], [Ge] and [O] respectively, was determined from the spectra fittings. Using these data, the $\mathrm{R}$ $(\mathrm{Si})=[\mathrm{Si}] /(2 \times[\mathrm{O}])$ and $\mathrm{R}(\mathrm{Ge})=[\mathrm{Ge}] /(2 \times[\mathrm{O}])$ ratios were calculated. These ratios are useful to determine if $\mathrm{Si}$ and $\mathrm{Ge}$ oxides are able to be formed and if it is possible to find $\mathrm{Si}$ and/or Ge atoms in excess in the films. The composition of the as-deposited and annealed oxide matrices was analyzed by Fourier transform infrared spectroscopy (FTIR). The FTIR spectra were acquired using a Perkin Elmer Spectrum 100 spectrometer in the 200 to $7800 \mathrm{~cm}^{-1}$ wavenumber range. The bare Si substrates were used as references to acquire the background in each case. The presence of amorphous and/or crystalline Si and Ge incorporated to the films as well as the existence of nanocrystals in the as-deposited and annealed samples was studied by Raman spectroscopy using visible $(514.5 \mathrm{~nm})$ and UV (325 $\mathrm{nm}$ line from a HeCd laser) excitations and a HR Labram Jobin-Yvon Raman spectrometer. Photoluminescence (PL) spectra, also excited using the $325 \mathrm{~nm}$ line of the same laser, were acquired at room temperature (RT).

\section{RESULTS AND DISCUSSION}

\section{$\underline{\text { As-deposited films }}$}

Figure 1 shows the RBS spectra of some of the as-deposited samples. Growth rates from 20 to $40 \mathrm{~nm}$ / hour are obtained, which are appropriate for the controlled deposition of a few nanometers thick layers. The $\mathrm{R}(\mathrm{Si})$ and $\mathrm{R}(\mathrm{Ge})$ atomic fractions defined above are represented in figure 2 as a function of the $\mathrm{GeH}_{4} / \mathrm{Si}_{2} \mathrm{H}_{6}$ gas flow ratio, ranging from $\mathrm{F}=0.2$ to $\mathrm{F}=2$. $\mathrm{R}(\mathrm{Ge})$ shows a linear dependence on $\mathrm{F}$ in the whole considered interval, indicating that an increasing amount of $\mathrm{Ge}$ atoms is being incorporated to the film as $\mathrm{F}$ increases. The value of $\mathrm{R}(\mathrm{Si})$, however, is almost constant and equal to 1 for $\mathrm{F}<1$, pointing to the existence of a $\mathrm{SiO}_{2}$ matrix with almost no $\mathrm{Si}$ in excess, and increases with $\mathrm{F}$ only for $\mathrm{F}>1$.

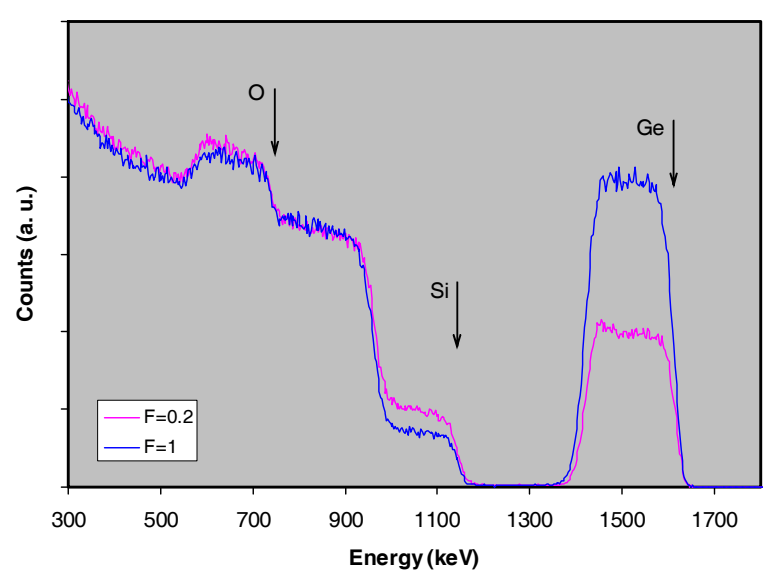

Figure 1. Selected RBS spectra of samples deposited using different values of $\mathrm{F}$.

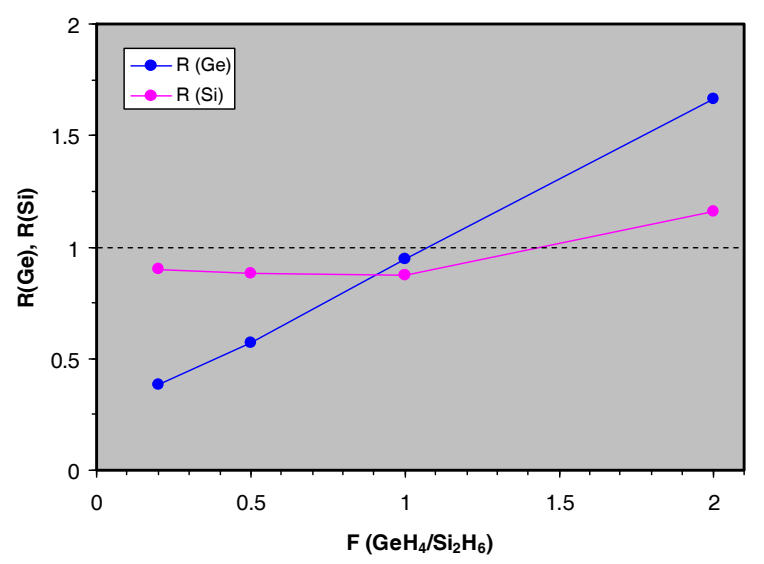

Figure 2. Atomic ratios (see text) determined from the RBS spectra as a function of F. 
The FTIR and Raman spectra, acquired using visible excitation, of the samples deposited with different values of $\mathrm{F}$ are displayed in figures 3 and 4 respectively. In the sample with $\mathrm{F}=0$, absorption bands were found in the FTIR spectra at around 463 (not included), 814 and 1070 $\mathrm{cm}^{-1}$, all of them related to $\mathrm{Si}-\mathrm{O}-\mathrm{Si}$ bonds. Another band appears around $875 \mathrm{~cm}^{-1}$, which is attributed in the literature to the bending mode of $\mathrm{Si}-\mathrm{H}$ bonds and also to the $\mathrm{SiH}_{2}$ scissors vibration. As F increases, the $\mathrm{Si}-\mathrm{O}-\mathrm{Si}$ related bands are also present in the spectra with similar intensities, while the intensity of the $\mathrm{Si}-\mathrm{H}$ related band decreases significantly.

For $\mathrm{F} \geq 1$ the $\mathrm{Si}-\mathrm{H}$ band disappears and another band (clearly visible in the spectrum of the sample deposited with $\mathrm{F}=2$ ) starts to appear at $995 \mathrm{~cm}^{-1}$, as a shoulder of the $1070 \mathrm{~cm}^{-1}$ one, which is related to $\mathrm{Si}-\mathrm{O}-\mathrm{Ge}$ bonds. The absorption bands around $1200 \mathrm{~cm}^{-1}$ are related to the existence of distortions in the $\mathrm{Si}-\mathrm{O}-\mathrm{Si}$ bonds and are found to increase in intensity with increasing $\mathrm{F}$ in the whole interval of values of $\mathrm{F}$. The existence of $\mathrm{Ge}-\mathrm{O}-\mathrm{Ge}$ bonds, which should introduce a band at around $885 \mathrm{~cm}^{-1}$ due to their stretching mode, is discarded since in the samples with a greater amount of Ge atoms no absorption band at all is observed in the vicinity of this wavenumber.
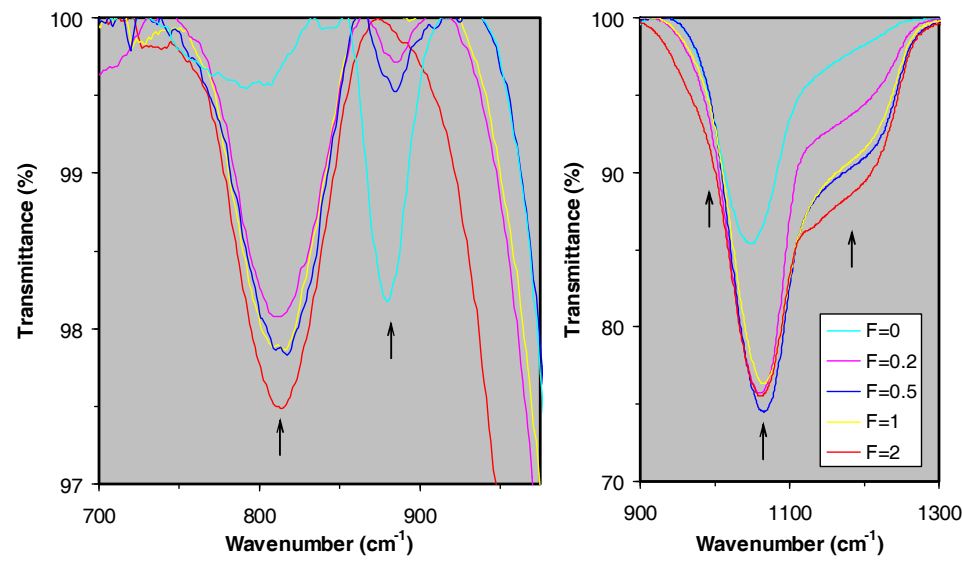

Figure 3. FTIR transmittance spectra of samples deposited with different values of $\mathrm{F}$.

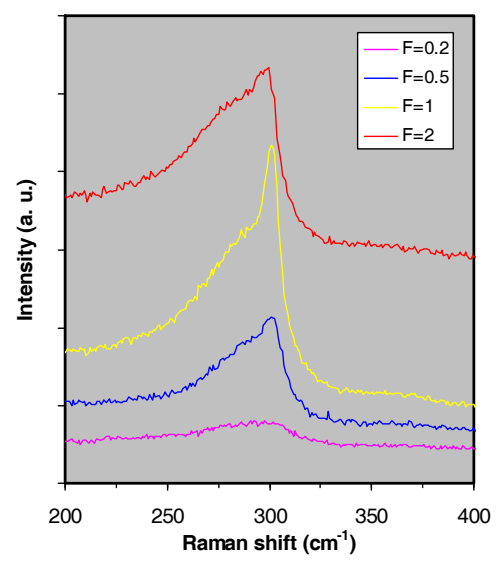

Figure 4. Ge-Ge band of the Raman spectra (see figure 3).

With regard to the Ge-Ge signal of the Raman spectra, the only one arising from the film that is visible, its presence in the spectra is a clear indication of the incorporation of Ge to the films. Moreover, the band is formed by a broad halo and a sharp peak located at $300 \mathrm{~cm}^{-1}$, which account for the simultaneous presence of amorphous and crystalline Ge respectively, with a relative weight which depends on the value of $\mathrm{F}$. The band corresponding to crystalline $\mathrm{Ge}$ presents phonon confinement, which suggests that crystalline Ge is arranged in clusters of a few nanometers in diameter [6]. The analysis of the Raman parameters concerning the intensities of the amorphous and crystalline bands and the full width at half maximun (FWHM) of the crystalline band shows that a) the total amount of Ge-Ge bonds increases as $\mathrm{F}$ does up to $\mathrm{F}=1$, while for higher values of $\mathrm{F}$ it decreases, $\mathrm{b}$ ) the relative amount of crystalline Ge respect to amorphous $\mathrm{Ge}$ also increases with increasing $\mathrm{F}$ up to $\mathrm{F}=1$ and decreases for higher $\mathrm{F}$, and c) The Ge cluster size increases with $\mathrm{F}$, at least up to $\mathrm{F}=1$, as the FWHM is found to decrease from 17 to around $8 \mathrm{~cm}^{-1}$.

These results are interpreted as follows. For low values of $\mathrm{F}(\mathrm{F}<1)$, the deposited material consists of almost stoichiometric Si oxide with an amount of Ge atoms incorporated to the film, 
in the form of amorphous and crystalline Ge, which depends on F. No evidences of the formation of Ge oxides are found. A small excess of Si probably exists, as the Si-H bands of the FTIR spectra indicate. Note that the possible excess of $\mathrm{Si}$ in the samples deposited with $\mathrm{F}>0$, related to the intensity of the $\mathrm{Si}-\mathrm{H}$ band, is much smaller than in the sample with $\mathrm{F}=0$ although the flow of $\mathrm{Si}_{2} \mathrm{H}_{6}$ is the same, $10 \mathrm{sccm}$, in all of them. The presence of Ge therefore reduces or almost inhibits the incorporation of $\mathrm{Si}$ in excess into the Si oxide films. For high values of $\mathrm{F}(\mathrm{F}>1)$ the deposited material consists of a matrix of mixed nature, formed by a mixture of $\mathrm{Si}$ and $\mathrm{SiGe}$ oxides of unknown proportions, also incorporating amorphous and crystalline Ge. Since part of the incoming $\mathrm{Ge}$ atoms are now incorporated to form the oxide matrix, the amount of $\mathrm{Ge}-\mathrm{Ge}$ bonds in the samples decreases with respect to the previous cases. In all the interval of values of $\mathrm{F}$, the incorporation of $\mathrm{Ge}$ and/or the formation of mixed oxides lead to the observed distortion of the structure of the $\mathrm{Si}$ oxide. The case $\mathrm{F}=1$, which corresponds to the situation where at least one atom of each kind, $\mathrm{Si}$ and $\mathrm{Ge}$, is present in the solid for each couple of oxygen atoms (see figure 2), represents the transition between the two different types of deposited materials.

\section{$\underline{\text { Annealed films }}$}

Figures 5 and 6 display selected FTIR and Raman spectra, in this case acquired using UV excitation to enhance the sensitivity of the technique to small amounts of amorphous and crystalline material, of the samples deposited with $\mathrm{F}=0.2$ and $\mathrm{F}=0.5$ and annealed at 600,800 and $1000{ }^{\circ} \mathrm{C}$ (the spectra of the corresponding as-deposited samples are displayed in figure 3 ).

The FTIR spectrum of the sample with $\mathrm{F}=0.2$ annealed at $600{ }^{\circ} \mathrm{C}$ shows the same bands and with almost the same intensities as the one of the as-deposited sample. Annealing at higher temperatures causes a slight but noticeable increase in the intensity of the absorption band at $875-885 \mathrm{~cm}^{-1}$. The band at $995 \mathrm{~cm}^{-1}$ also starts to appear. Considering now the sample of $\mathrm{F}=0.5$, it is found that the intensity of the $875-885 \mathrm{~cm}^{-1}$ and at $995 \mathrm{~cm}^{-1}$ bands increase substantially after annealing at a temperature of $600{ }^{\circ} \mathrm{C}$ or higher. Since no hydrogen could exist in the sample after annealing at these temperatures, the $875-885 \mathrm{~cm}^{-1}$ band should be attributed to an increasing amount of Ge-O-Ge bonds in the film. On the other hand, the band at $995 \mathrm{~cm}^{-1}$ evidences the presence of $\mathrm{Si}-\mathrm{O}-\mathrm{Ge}$ bonds and therefore the formation of a mixed oxide.
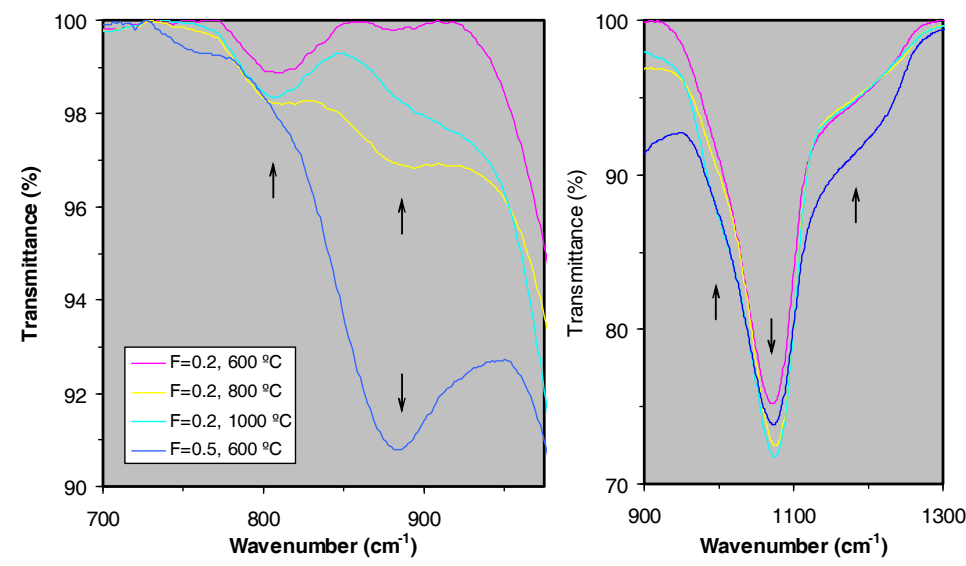

Figure 5. FTIR transmittance spectra of the samples deposited with $\mathrm{F}=0.2$ and $\mathrm{F}=0.5$ and annealed at different temperatures.

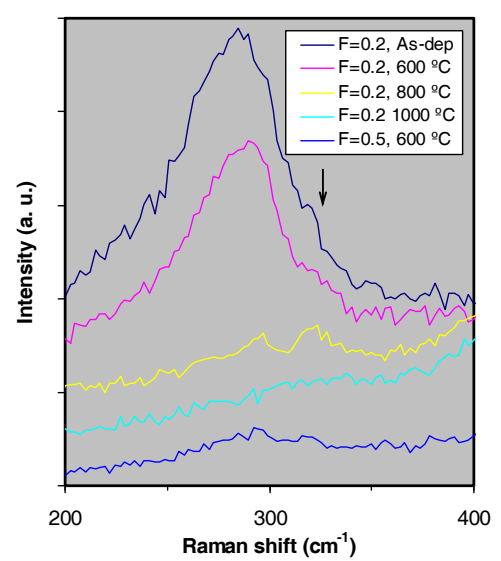

Figure 6. Ge-Ge signal of the Raman spectra (see figure 5). 
The Raman spectra of the sample deposited with $\mathrm{F}=0.2$ show that after the $600{ }^{\circ} \mathrm{C}$ annealing process the intensity of the Ge-Ge band has only slightly decreased, indicating that the annealed film contains a slightly smaller amount of $\mathrm{Ge}-\mathrm{Ge}$ bonds than the as-deposited one. Annealing at $800{ }^{\circ} \mathrm{C}$ causes the Ge-Ge band to almost disappear (the small peak around $325 \mathrm{~cm}^{-1}$, indicated by an arrow in figure 6 , is an instrumental artifact). Increasing the temperature up to $1000{ }^{\circ} \mathrm{C}$ causes the $\mathrm{Ge}-\mathrm{Ge}$ band to be fully absent in the Raman spectrum. With regard to the sample with $\mathrm{F}=0.5$, annealing at $600^{\circ} \mathrm{C}$ is enough to cause the $\mathrm{Ge}-\mathrm{Ge}$ band to almost vanish (note from figure 4 that the Ge-Ge band in the spectrum of the as-deposited sample is much more intense than in the one of the sample with $\mathrm{F}=0.2$ ).

The interpretation of these results is as follows. The sample deposited with $\mathrm{F}=0.2$ holds its structure, consisting of a matrix of Si oxide incorporating amorphous and crystalline Ge, after annealing at $600{ }^{\circ} \mathrm{C}$. The slight reduction in the amount of Ge atoms is also accounted by RBS (not shown) to correspond to Ge loss by outdiffusion, and no evidences of the formation of $\mathrm{Ge}$ oxides are found. However, the matrix is transformed into a mixture of $\mathrm{Si}, \mathrm{Ge}$ and $\mathrm{SiGe}$ oxides for higher annealing temperatures. In the sample with $\mathrm{F}=0.5$, this transformation is observed, to a much greater extent, even at $600{ }^{\circ} \mathrm{C}$. A similar description holds for the samples with higher values of $\mathrm{F}$. In the cases where Ge related oxides appear upon annealing, a clear correlation with the reduction of the intensity of the Ge-Ge band in the Raman spectra is found, since some Ge is now bonded to open oxygen bridge bonds.

Figure 7 shows the PL spectra of the samples deposited with different values of $F$ from $\mathrm{F}=0$ to $\mathrm{F}=2$ and annealed at $600{ }^{\circ} \mathrm{C}$. A spectrum of a bare $\mathrm{Si}$ wafer is also included as a reference of the background. The spectra present two bands, a blue-violet band around $400 \mathrm{~nm}$ (VL) and a broad band between 500 and $600 \mathrm{~nm}$ (GYL). The VL band was described in a previous paper [7], and its origin is attributed to oxygen deficient centers at the interface between the Ge nanocrystals and the oxide shells. The presence of Ge oxide in the films after annealing does not enhance the VL band, which confirms that it does not arise from the bulk of the Ge oxide. On the other hand, the GYL band is related to defects in the Si oxide. Figure 8 shows the evolution of the intensity of the VL band with the annealing temperature for samples deposited with different values of $\mathrm{F}$.

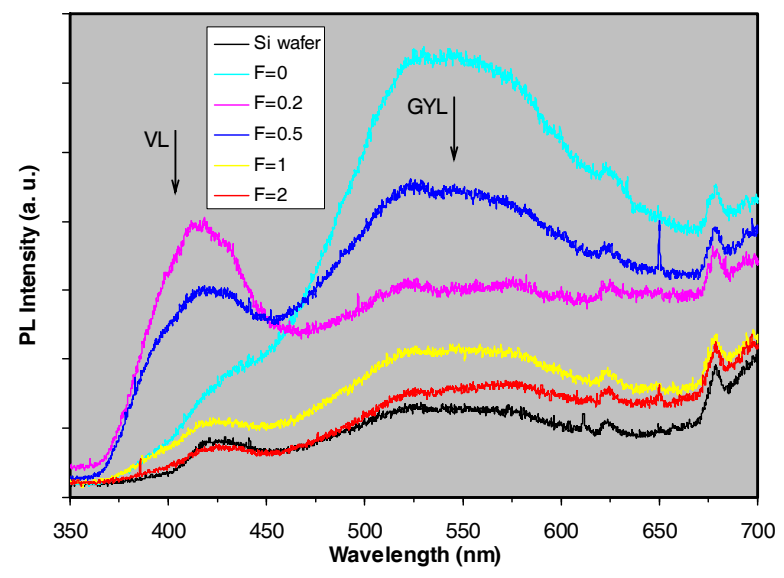

Figure 7. PL spectra of samples deposited with different values of $\mathrm{F}$ and annealed at $600^{\circ} \mathrm{C}$.

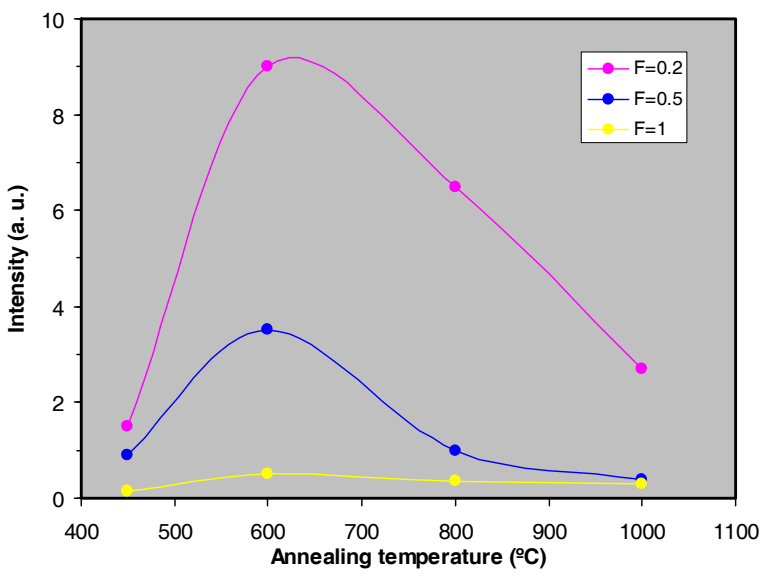

Figure 8. Intensity of the VL (400 nm) PL band as a function of the annealing temperature. 
The VL band does not exist in the sample with $\mathrm{F}=0$, which does not incorporate $\mathrm{Ge}$, and its intensity is, at all the annealing temperatures, very small in the sample with $\mathrm{F}=1$ and negligible in the sample with $\mathrm{F}=2$. This band is observed in all the samples where the Raman spectra reveal the presence of Ge nanocrystals. Its intensity reaches a maximum value after annealing a $600{ }^{\circ} \mathrm{C}$ and then starts to decrease for higher annealing temperatures. The maximum intensity of the VL band is observed for the sample deposited with $\mathrm{F}=0.2$ and annealed at $600{ }^{\circ} \mathrm{C}$, in which Ge nanocrystals are observed and the matrix does not evidence the formation of mixed oxides.

\section{CONCLUSIONS}

The fabrication of nanostructures with nanocrystals embedded in an oxide matrix by LPCVD of SiGeO films and annealing has been demonstrated. The influence flow ratio of the reactant gases and the annealing temperature on the composition of the oxide matrix and the nature of the nanocrystals have been studied. The nanocrystals are predominantly of Ge for all compositions of the gas, while the matrix is Si oxide only if the flow of the precursor of Ge kept low. The maximum intensity of the photoluminescence band $(400 \mathrm{~nm})$ related to the presence of nanocrystals has been obtained in the sample deposited with a low flow of the precursor of $\mathrm{Ge}$ and annealed at $600{ }^{\circ} \mathrm{C}$.

\section{ACKNOWLEDGMENTS}

This work was funded by the Spanish CICYT Project MAT2004-04580.

\section{REFERENCES}

1. U. V. Desnica et al. Superlattices and Microstructures (2008), in press (DOI: 10.1016/j.spmi.2008.01.021).

2. E. W. H. Kan, W. K. Choi, W. K. Kim, E. A. Fitzgerald, D. A. Antoniadis. J. Appl. Phys. 95 (2004) 3148.

3. A. Rodríguez, M. I. Ortiz, J. Sangrador, T. Rodríguez, M. Avella, Á. C. Prieto, A. Torres, J. Jiménez, A. Kling, C. Ballesteros. Nanotechnology 18 (2007) 065702 and references threin.

4. A. Rodríguez, M. I. Ortiz, J. Sangrador, T. Rodríguez, M. Avella, Á. C. Prieto, J. Jiménez, A. Kling, C. Ballesteros. Phys. Stat. Sol. (a) 204 (2007) 1639 and references therein.

5. L. R. Doolittle, Nucl. Instr. and Meth. 9 (1985) 344, The latest version of this program can be found at http://www.genplot.com

6. H. Campbell, P. M. Fauchet. Solid State Commun. 58 (1986) 739.

7. M. Avella, Á.C. Prieto, J. Jiménez, A. Rodríguez, J. Sangrador, T. Rodríguez. Solid State Communications 136 (2005) 224 and references therein. 